\section{(1) \\ CrossMark}

\title{
Management of chronic respiratory complications in children and adolescents with sickle cell disease
}

\author{
Michele Arigliani (ib ${ }^{1,2}$ and Atul Gupta (10) 3,4
}

Affiliations: ${ }^{1}$ Dept of Medicine, University Hospital of Udine, Udine, Italy. ${ }^{2}$ Paediatric Respiratory Medicine and Lung Transplantation, Great Ormond Street Hospital for Children, and UCL Institute of Child Health, London, UK. ${ }^{3}$ Dept of Paediatric Respiratory Medicine, King's College Hospital NHS Foundation Trust, London, UK. ${ }^{4}$ Institute for Women's and Children's Health, King's College London, London, UK.

Correspondence: Atul Gupta, Dept of Paediatric Respiratory Medicine, King's College Hospital, Denmark Hill, London, SE5 9RS, UK. E-mail: atul.guptaakcl.ac.uk

@ERSpublications

Respiratory disease has a high burden in sickle cell disease (SCD), with chronic pulmonary complications often beginning in childhood. We provide an overview of pathophysiology and therapeutic aspects of chronic respiratory disease in children with SCD. https://bit.ly/3165pNk

Cite this article as: Arigliani M, Gupta A. Management of chronic respiratory complications in children and adolescents with sickle cell disease. Eur Respir Rev 2020; 29: 200054 [https://doi.org/10.1183/ 16000617.0054-2020].

ABSTRACT Sickle cell disease (SCD) is a life-threatening hereditary blood disorder that affects millions of people worldwide, especially in sub-Saharan Africa. This condition has a multi-organ involvement and highly vascularised organs, such as the lungs, are particularly affected. Chronic respiratory complications of SCD involve pulmonary vascular, parenchymal and airways alterations. A progressive decline of lung function often begins in childhood. Asthma, sleep-disordered breathing and chronic hypoxaemia are common and associated with increased morbidity. Pulmonary hypertension is a serious complication, more common in adults than in children. Although there is a growing attention towards respiratory care of patients with SCD, evidence regarding the prognostic meaning and optimal management of pulmonary issues in children with this condition is limited. This narrative review presents state-of-the-art evidence regarding the epidemiology, pathophysiology and therapeutic options for chronic respiratory complications commonly seen in paediatric patients with SCD. Furthermore, it highlights the gaps in the current knowledge and indicates future directions for studies that aim to improve our understanding of chronic respiratory complications in children with SCD.

\section{Introduction}

Sickle cell disease (SCD) is the most common hereditary blood disorder in people of African ancestry, affecting around 14000 people in the UK alone [1].

In this condition, recurrent episodes of red blood cell sickling, haemolysis and microvascular occlusion trigger a cascade of events resulting in a wide range of symptoms, as well as chronic vasculopathy and multiple end-organ damage [2]. Highly vascularised organs, such as brain, kidneys, spleen and the lungs, are particularly affected. Respiratory disease is among the leading causes of morbidity and mortality in SCD, with death most commonly occurring in the context of severe acute chest syndrome, pulmonary embolism and/or pulmonary hypertension [3]. There is increasing focus on respiratory care of patients with SCD, and the number of studies investigating respiratory complications has markedly increased in recent years [4].

Provenance: Submitted article, peer reviewed

Received: 26 Feb 2020 | Accepted after revision: 14 June 2020

Copyright $\odot$ ERS 2020. This article is open access and distributed under the terms of the Creative Commons Attribution Non-Commercial Licence 4.0. 
These complications often begin in childhood [5], and most of them are also associated with a more severe course of disease. Therefore, it is important that paediatricians are aware of and recognise precocious respiratory signs/symptoms that necessitate appropriate assessment and management in children with SCD.

In this narrative review, we aim to provide a brief overview of chronic respiratory issues in children with SCD and a practical understanding of how to investigate and manage conditions such as asthma, lung function abnormalities, sleep-disordered breathing (SDB), hypoxaemia, pulmonary hypertension and reduced exercise capacity in this group. Given that the most severe manifestations of SCD and most of the published evidence concern people with haemoglobin SS disease or sickle $\beta$-zero thalassaemia, we will focus on these phenotypes.

Findings from relevant studies in the field will be presented and will be integrated with the authors' intuitive, experiential and explicit perspectives in the areas where evidence is missing. An extensive literature search was carried out at this scope and was limited to PubMed. However, since this was not a systematic review, we cannot dismiss that some relevant studies may have been omitted.

\section{Lung function abnormalities}

Lung function abnormalities are frequently noted in children and adolescents with SCD, who may have a progressive decline of lung function with age $[6,7]$. Comparison of results between older studies is hindered by the fact that many different reference values and criteria for defining lung function abnormalities have been used, as previously reviewed by KoumbourLis et al. [8]. Nowadays, the availability of the 2012 Global Lung Initiative reference values for spirometry [9], including prediction equations for African-Americans that have also been validated in sub-Saharan Africa [10], provides a useful tool to compare lung function in patients with SCD from different countries. When interpreting lung function results in this group, it is important that the lower limit of normal (LLN) is established at the 5th percentile (-1.64 z-scores) of the reference population instead of using a fixed cut-off (e.g. $80 \%$ of predicted), which can lead to misclassification of the lung function pattern $[8,11]$. Combining the results of dynamic and static lung volume measures (i.e. spirometry and body plethysmography), it is then possible to identify five different respiratory patterns in patients with SCD: normal, restrictive, obstructive, mixed and nonspecific (figure 1) [12]. Using such classification, CoHEN et al. [12] reported an abnormal lung function in $30 \%$ of children and adolescents with SCD (16\% obstruction, $7 \%$ restriction, $1 \%$ mixed and $6 \%$ nonspecific pattern).

In paediatric patients with SCD from high-income countries, an obstructive physiology (forced expiratory volume in $1 \mathrm{~s}\left(\mathrm{FEV}_{1}\right) /$ forced vital capacity $(\mathrm{FVC})$ ratio $<\mathrm{LLN}(<5$ th percentile) and total lung capacity $(\mathrm{TLC}) \geqslant \mathrm{LLN}$ ) is the most frequent lung function alteration, noted in approximately $15-20 \%$ of the cases $[12,13]$. In low- to middle-income countries, however, cross-sectional spirometry data in children with SCD aged 6-19 years showed that $25-30 \%$ of participants had reduced $\mathrm{FEV}_{1}$ and FVC $<5$ th percentile

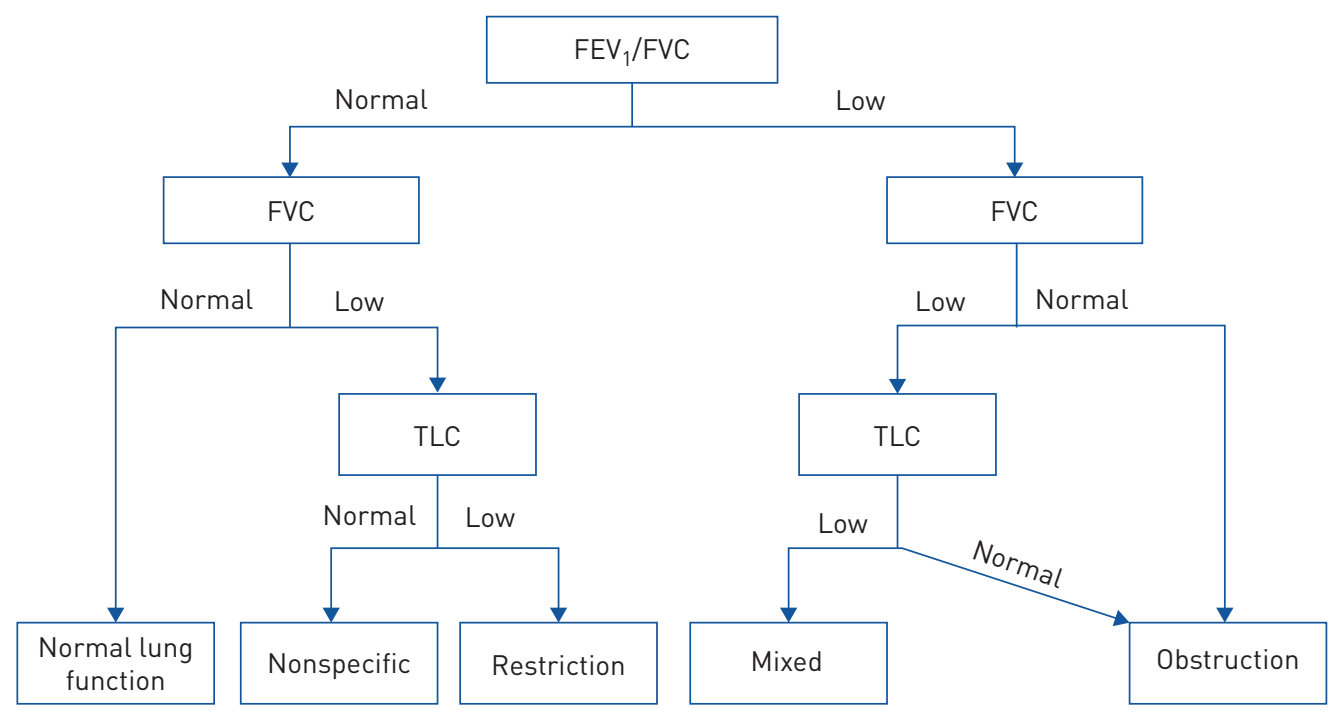

FIGURE 1 Diagnostic algorithm to assess lung function abnormalities in children with sickle cell disease. $\mathrm{FEV}_{1}$ : forced expiratory volume in $1 \mathrm{~s}$; FVC: forced vital capacity; TLC: total lung capacity; low: lower limit of normal (5th percentile of the reference population); normal: $\geqslant 5$ th percentile. Reproduced from [12] with permission of the American Thoracic Society. 
with preserved $\mathrm{FEV}_{1} / \mathrm{FVC}$ ratio, possibly indicating a restrictive (TLC $<\mathrm{LLN}$ ) or nonspecific pattern (TLC $\geqslant$ LLN) $[14,15]$. Diffusing capacity (adjusted for haemoglobin values) can also be impaired in paediatric patients with SCD [13], more often in adolescents with a restrictive physiology [16].

It is not clear whether any intervention is able to slow down the deterioration of lung function with age that is often seen in people with this condition. However, a retrospective analysis of 56 children and adolescents with SCD aged $>5$ years showed that, after starting hydroxyurea, the annual rate of decline in $\mathrm{FEV}_{1}$ was less pronounced in the study group than in 75 patients who did not receive this therapy [17].

The pathophysiology of lung function abnormalities in children with SCD is still not well defined. Obstructive physiology (figure 1) is not limited to patients with asthma [12, 13]. An alternative mechanism may be the compression of small airways by congested peripheral pulmonary vessels, as suggested by the correlation between pulmonary capillary blood volume and airflow limitation [18].

On the other hand, in adult SCD patients with a restrictive lung function pattern (figure 1), reduced spirometry indices and TLC correlated with lobar volume loss on high-resolution computed tomography [19], which is common in fibrotic lung disease. FIELD et al. [20] demonstrated higher levels of circulating activated fibrocytes in SCD patients with impaired $\mathrm{FEV}_{1}$ and FVC, which could contribute to the pathogenesis of lung fibrosis [21]. However, interstitial pulmonary fibrosis does not seem to be the only mechanism responsible for loss of lung volume in this group [22].

In the authors' opinion, different lung function patterns in paediatric patients with SCD, except for an obstructive physiology associated with allergic asthma, do not necessarily identify different phenotypes but rather represent the spectrum of SCD-related chronic lung disease, which affects airways, parenchyma or pulmonary vasculature. Longitudinal prospective data show, however, that even in the paediatric population, the incidence of restrictive lung function alterations in individuals with SCD increases with age [7], probably as a result of the progression of pulmonary end-organ damage.

The clinical and prognostic meaning of lung function alterations in children with SCD is uncertain, due to the paucity of long-term longitudinal data and the use of various interpretative strategies across different studies [4]. Abnormal lung function patterns are not associated with past or future rates of pain [12], whereas there is conflicting data regarding the relationship with future acute chest syndrome episodes $[7,12]$. Provided that in adults with SCD a reduced $\mathrm{FEV}_{1}$ is associated with earlier mortality [23], we suggest that paediatric patients with this condition undergo annual spirometry from the age of 6 years [5], with more frequent assessments and static lung volume measurements for those with abnormal lung function and/or asthma. These latter subjects should also be periodically evaluated by a paediatric pulmonologist. A chest computed tomography scan to assess the degree of pulmonary fibrosis may be considered in patients with moderate/severe restrictive or mixed lung function pattern.

\section{Asthma and wheezing}

In a large prospective cohort study, a doctor diagnosis of asthma was reported in $17-28 \%$ of children with SCD [24-26] and was associated with a higher risk of vaso-occlusive pain crises [24, 25], acute chest syndrome [24-26] and premature death [27]. The mechanisms linking asthma and increased morbidity in SCD have not been elucidated to date. Miller et al. [28] proposed that asthma-induced ventilationperfusion mismatch may cause local tissue hypoxia and subsequent sickling of the red cells, triggering the cascade of pathophysiology events leading to SCD respiratory complications.

Asthma is far more common in paediatric SCD patients with allergies than in those without: in an unselected cohort of 187 children and adolescents with SCD, 45\% of those with a physician diagnosis of asthma had at least two skin prick tests positive for common aeroallergens, compared with only $15 \%$ of participants without asthma [26]. However, chronic airway inflammation and airway remodelling may also develop simply due to SCD pathophysiology, causing asthma or isolated recurrent wheezing [26], airway hyperresponsiveness [29] or obstructive lung function [12]. Evidence from animal and human studies suggests that several mechanisms are involved in SCD airway disease, including exaggerated allergic airway inflammation after sensitisation [30] and activation of inflammatory pathways following ischaemia-reperfusion injury in the lung [31]. Moreover, downstream products of the haemolytic arginine-nitric oxide pathway may contribute to asthma and airway remodelling [32], as well as the increased levels of cysteinyl leukotrienes and leukotriene $\mathrm{B}_{4}$ in SCD patients (involved in eosinophilic asthma and neutrophilic inflammation, respectively) [33, 34]. Overall, these mechanisms result in increased levels of T-helper 1, T-helper 2 and monocytic inflammatory markers in patients with SCD and asthma or asthma-like features compared with non-SCD subjects with atopic asthma [35].

The overlap of wheezing phenotypes makes the diagnosis of asthma in children with SCD challenging. STRUNK et al. [26] reported that almost half of SCD paediatric patients without an asthma diagnosis had 
experienced wheezing in the past, whereas the presence of at least two characteristics among having a parent with asthma, wheezing with exercise and wheezing causing shortness of breath had a sensitivity of $100 \%$ for doctor diagnosis of asthma [26]. The demonstration of airflow obstruction reversible with bronchodilators supports the diagnosis but non-reversible lower airway obstruction can also be found as part of the SCD-related chronic airway disease [36]. Exhaled nitric oxide fraction $\left(F_{\mathrm{ENO}}\right)$ has been reported at higher, lower or similar levels compared with control subjects [37-39]. CoHEN et al. [40] found that in 131 children with SCD, higher $F_{\mathrm{ENO}}$ levels were associated with atopic features (positive skin-prick test, raised immunoglobulin-E levels and peripheral blood eosinophil count) but not wheeze, baseline spirometric indices or bronchodilator response. An allergy assessment including history and skin prick tests (or blood radioallergosorbent test) for aeroallergens should be performed in SCD patients with suspicion of asthma [26]. Finally, an asthma diagnosis should be ruled out in patients with recurrent episodes of acute respiratory distress interpreted as acute chest syndrome despite negative chest radiograph findings, given the overlap of symptoms between the two conditions (e.g. wheezing, cough, chest pain, shortness of breath) [41].

There is a lack of evidence regarding acute and chronic asthma treatment for patients with SCD. For those with an acute asthma attack, in our practice we apply a low threshold for hospital admission and chest radiography, in light of the differential with acute chest syndrome. Hypoxaemia compared to the baseline should be promptly treated as it triggers red cell sickling and, potentially, further complications [42]. Apart from short-acting $\beta_{2}$-agonists, oral corticosteroids can be administered for moderate or severe exacerbations, although they should be used with caution due to a reported association with vaso-occlusive pain [43]. When needed, we suggest a 3-day course of $1 \mathrm{mg} \cdot \mathrm{kg}^{-1}$ per day ( $\mathrm{max} 40 \mathrm{mg}$ ) of prednisolone-equivalent dose.

For SCD patients with frequent asthma symptoms that require regular preventer therapy, we follow a step-wise therapeutic approach based on national and international guidelines for the management of asthma in children $[44,45]$. A poor clinical response to escalating doses of inhaled corticosteroids (ICS) in SCD patients with asthma may depend on inadequate delivery of ICS to lungs (e.g. poor compliance to ICS, use of wrong inhaler, poor inhaler technique), comorbidities (e.g. allergic rhinitis, dysfunctional breathing) or the presence of a predominant non-eosinophilic component of airway inflammation [35], or may indicate the need to reconsider the appropriateness of diagnosis. Given the potential role of the leukotriene pathway in the pathogenesis of SCD-related morbidity [46], we often use cysteinyl leukotriene receptor antagonist (montelukast) for chronic asthma prophylaxis in this group. A higher risk of neuropsychiatric adverse effects (including irritability, aggressiveness and sleep disturbances) was reported with montelukast than with ICS in children with asthma (relative risk 12.0, 95\% CI 1.60-90.2) [47]. These symptoms usually appear in the first week of therapy [48], in which case the drug should be stopped.

The routine use of spirometry along with standardised asthma control questionnaires [49] can be useful to evaluate the response to treatment, although these tools have not been validated for such scope in the SCD population.

\section{SDB and hypoxaemia}

SDB with nocturnal hypoxaemia is common in children with SCD. Obstructive sleep apnoea (OSA) affects approximately $40 \%$ of children of African ancestry with SCD when using an obstructive apnoeahypopnoea index cut-off point $\geqslant 1$ at polysomnography (PSG) or $10 \%$ at cut-off point $\geqslant 5$ [50]. Over one-third of children with SCD will also have sustained daytime hypoxaemia (oxygen saturation measured by pulse oximetry $\left.\left(S_{\mathrm{pO}_{2}}\right)<96 \%\right)[51,52]$, which can depend on the variable combination of lung parenchyma, airways and vasculature alterations leading to reduced gas-exchange and ventilation-perfusion mismatch. Moreover, the polymerisation of haemoglobin $\mathrm{S}$ ( $\mathrm{HbS}$ ) causes a right-shift of the oxyhaemoglobin dissociation curve (i.e. decreased haemoglobin oxygen affinity) [53], determining an oxyhaemoglobin saturation at a given arterial partial pressure of oxygen lower than predicted by a normal oxyhaemoglobin dissociation curve [42].

The gold standard measure of oxyhaemoglobin saturation in patients with SCD is arterial blood gas analysis with co-oximeter or, as an alternative, noninvasive pulse co-oximetry. The use of co-oximetry allows measurement of the fractional oxyhaemoglobin saturation, which is the proportion of total haemoglobin oxygenated [42]. The oxyhaemoglobin saturation obtained by conventional two-wavelength pulse oximetry presents less discrepancies with co-oximetry than traditional arterial blood gas [54], where oxyhaemoglobin saturation is calculated from the arterial oxygen tension and the oxyhaemoglobin dissociation curve of haemoglobin A, which is not applicable to individuals with SCD.

However, the use of two-wavelength pulse oximetry in SCD presents some caveats, mainly because of the increased levels of carboxyhaemoglobin and methaemoglobin in these patients [55]. Such dysfunctional 
haemoglobins are unable to carry oxygen but adsorb light at similar wavelengths as oxygenated and deoxygenated haemoglobin, affecting $S_{\mathrm{pO}_{2}}$ readings [42]. Of note, low $S_{\mathrm{pO}_{2}}$ values during pulse oximetry in patients with SCD may be simply due to digit hypoperfusion (i.e. acute dactylitis). Therefore, in cases of low $S_{\mathrm{pO}_{2}}$ it is always advisable to obtain a second reading from another site (e.g. earlobe) to confirm the finding. Moreover, it should be kept in mind that oxyhaemoglobin saturation is only one of the determinants of the total amount of oxygen that can reach the tissues, with haemoglobin concentration, cardiovascular function and oxygen release from haemoglobin also playing an important role [56].

Oxyhaemoglobin desaturation triggers HbS polymerisation, which is the first of a chain of events culminating in SCD complications [2]. Moreover, in the presence of SDB, the repeated cycles of hypoxia and re-oxygenation enhance the oxidative stress and pro-inflammatory signalling pathways that contribute to cause SCD-related acute and chronic manifestations [57].

Current evidence suggests that children with SCD and nocturnal hypoxaemia are at higher risk of intracranial arteriopathy [58] and central nervous system events [59], while a lower daytime $S_{\mathrm{pO}_{2}}$ resulted in an increased risk of stroke [60]. A higher frequency of left ventricular diastolic dysfunction has been reported in those with both asleep and waking oxygen desaturation [61], and there is evidence of increased risk of pulmonary hypertension, as suggested by a tricuspid regurgitation velocity (TRV) $>2.5 \mathrm{~m} \cdot \mathrm{s}^{-1}$ at Doppler echocardiography in paediatric patients with lower awake $S_{\mathrm{pO}_{2}}[62,63]$. Enuresis is more frequent in SCD children with OSA [50], whereas most recent prospective studies did not find an association between overnight $[52,64]$ or daytime $[52,65] S_{\mathrm{pO}_{2}}$ and the incidence of vaso-occlusive pain crises and acute chest syndrome in paediatric SCD patients.

Given the clinical implications of nocturnal hypoxaemia in children with SCD, it is important to specifically investigate the presence of SDB symptoms in these patients, such as snoring, daytime somnolence, morning headaches, hyperactivity or behavioural disturbance, enuresis continuing after 6 years of age and observed apnoeas during sleep. In the presence of such symptoms, we suggest undertaking a sleep study, possibly a PSG. Recent British guidelines recommend investigating overnight oxygen saturation in SCD paediatric patients with spot daytime $S_{\mathrm{pO}_{2}}<95 \%$ [66]. Those with mean overnight $S_{\mathrm{pO}_{2}}<95 \%$ should then undergo PSG, assessment for cerebrovascular disease, and static and dynamic lung volumes measurement, and they should be considered for echocardiography [66].

Furthermore, we usually perform a hypoxia challenge test in SCD patients with waking $S_{\mathrm{PO}_{2}}<95 \%$ when fitness to fly is requested. In fact, during commercial flights in pressurised aircrafts, pressure of oxygen falls to the equivalent of breathing $15 \%$ oxygen (instead of $21 \%$ ) at sea level [67]. As a consequence, patients with SCD and low baseline $S_{\mathrm{pO}_{2}}$ may develop severe in-flight hypoxaemia, potentially triggering vaso-occlusive pain crises and other SCD-related complications [68].

Management of OSA in children with SCD includes conservative therapeutic attempts with nasal corticosteroids and/or montelukast administered for 6-12 weeks, tonsillectomy and adenoidectomy and the use of nocturnal continuous positive airway pressure [69].

Hydroxyurea significantly improved both overnight and daytime $S_{\mathrm{pO}_{2}}$ [70] in a retrospective cohort of 43 paediatric SCD patients, and it is currently indicated for treating chronic hypoxaemia in the UK (grade 1C) [71]. Nocturnal home oxygen therapy is an alternative option for SCD patients with chronic severe hypoxaemia. The recent American Thoracic Society guidelines for home oxygen therapy in children indicated that oxygen supplementation at home should be considered for SCD patients who have at least $5 \%$ of recording time spent with an $S_{\mathrm{pO}_{2}}<90 \%$ during a sleep study or at least three separate spot daytime $S_{\mathrm{pO}_{2}}$ records at steady state $<90 \%$ (conditional recommendation) [72]. There are concerns about the safety of long-term home oxygen therapy in patients with SCD, especially in terms of possible erythropoiesis suppression. In fact, oxygen may inhibit the hypoxia-inducible transcription factors which trigger erythropoietin production in kidney and liver and enhance maturation of erythroid progenitors in the bone marrow [73]. Some previous reports showed indeed impaired erythropoiesis when administering continuous high flow oxygen for several days in acutely ill patients with SCD [74, 75]. However, more recently, two retrospective reviews of adults [76] and children (unpublished data) with SCD undergoing long-term nocturnal home oxygen therapy demonstrated a good safety profile without detrimental effects on erythropoiesis.

\section{Exercise tolerance}

Children with SCD may have reduced tolerance of both moderate (6-min walk distance (6MWD)) [62, 77] and maximal exercise [78, 79]. Factors associated with poor cardiorespiratory fitness in SCD include the degree of anaemia and low fetal haemoglobin levels [77], the presence of left ventricular diastolic dysfunction [80] and restrictive lung disease [81], whereas a TRV $\geqslant 2.5 \mathrm{~m} \cdot \mathrm{s}^{-1}$ at echocardiography is associated with a greater decline by time of age-standardised 6MWD [82]. Exercise-induced 
bronchospasm/asthma can also cause poor exercise tolerance, and an exercise bronchial challenge test could highlight this.

There have been concerns regarding possible adverse effects of high-intensity exercise in patients with SCD as it induces changes that could trigger red blood cell sickling, such as dehydration, moderate temperature changes, lactic acid production, acute inflammation and oxidative stress [83]. However, though evidence is still limited, a regular moderate exercise programme in SCD patients (excluding contact sports, especially in those with splenomegaly) might have several positive effects, including favouring social inclusion and improving overall inflammation and oxidative stress [84].

Given these premises and pending further evidence, we generally suggest that paediatric patients with SCD undertake regular non-intensive exercise activity, and recommend that: 1) they avoid contact sports and exposure to extreme temperatures; 2) they start the exercise gradually and interrupt it if they are tired; 3 ) they keep well hydrated before, during and after the sport activity; and 4) a pre-exercise treatment with bronchodilator is used for those with exercise-induced bronchospasm.

\section{Pulmonary hypertension}

Pulmonary hypertension $(\mathrm{PH})$ is a known risk factor for earlier mortality in adults with SCD [85, 86]. The transthoracic echocardiogram is the most important noninvasive screening tool for $\mathrm{PH}$, though the definitive diagnosis requires right heart catheterisation with the demonstration of a mean pulmonary artery pressure (mPAP) $>20 \mathrm{mmHg}$ [87]. Previous studies reported a frequency of mPAP $\geqslant 25 \mathrm{mmHg}$ (previous cut-off for $\mathrm{PH}$ ) in $6-10 \%$ of adults with $\operatorname{SCD}[85,86]$, whereas there are no right heart catheterisation data in paediatric patients with SCD.

Haemodynamically, subjects with SCD may have mainly pre-capillary PH with thickened pulmonary arteriolar walls, or post-capillary $\mathrm{PH}$, secondary to left heart dysfunction [88]. Affected patients frequently have haemodynamic features of both components [89]. Alongside a mPAP $>20 \mathrm{mmHg}$, pre-capillary $\mathrm{PH}$ is characterised by increased pulmonary vascular resistance (PVR; $>3$ Wood Units) and pulmonary artery wedge pressure $\leqslant 15 \mathrm{mmHg}$, as opposed to post-capillary $\mathrm{PH}$ [87]. However, it should be borne in mind that baseline PVR values in individuals with SCD are lower than normal due to anaemia-induced increased cardiac output [88], and a PVR value $>2$ Wood Units is often considered high in these patients [89]. The aetiology of pre-capillary PH in SCD is multifactorial, potentially involving vasculopathy secondary to haemolysis, nitric oxide deficiency and hypoxia, besides chronic pulmonary thromboembolism [88]. Symptoms of $\mathrm{PH}$ are nonspecific and may include fatigue, dyspnoea (particularly on exertion), chest pain and syncope, whereas signs of right heart failure at physical examination will only appear at advanced stages of disease. Accompanying desaturation with exertion would increase suspicion of $\mathrm{PH}$.

The echocardiographic screening is based on a combined assessment of TRV measurement (threshold $2.8 \mathrm{~m} \cdot \mathrm{s}^{-1}$ ) and signs suggestive of $\mathrm{PH}$, such as right atrial enlargement, right ventricular dilation or hypertrophy, right-to-left septum shift and enlarged inferior cava diameter with decreased inspiratory collapse [90].

In a prospective cohort study including $160 \mathrm{HbSS}$ individuals aged 3-20 years, a TRV $>2.5 \mathrm{~m} \cdot \mathrm{s}^{-1}$ at baseline was reported in $14 \%$ of cases and was associated with greater haemolysis and oxygen desaturation at baseline, as well as with increased odds of decline in exercise capacity at a median follow-up of 22 months [82].

The American Thoracic Society guidelines suggest screening for PH patients with SCD between 8 and 18 years of age through a one-time Doppler echocardiography [89]. Those with an echocardiographic probability of $\mathrm{PH}$ that is intermediate to high should be referred to a $\mathrm{PH}$ centre experienced in SCD [90].

There is no evidence regarding the most adequate treatment for paediatric patients with SCD and PH [89]. Supplemental oxygen is given for hypoxaemia, aiming to obtain a $S_{\mathrm{pO}_{2}} \geqslant 90 \%$ at rest, during exertion and sleep [89]. Treatment of eventual respiratory comorbidities, such as asthma or OSA, seems to have a beneficial effect also on TRV [91]. The use of hydroxyurea as first-line treatment, with chronic transfusions as an alternative, is recommended [89].

\section{Future directions}

Long-term prospective follow-up studies in children with SCD and chronic respiratory issues are needed in order to clarify the prognostic meaning of specific conditions, such as lung function abnormalities, chronic hypoxaemia or elevated TRV at echocardiography, and whether therapeutic interventions, such as hydroxyurea, and new emerging disease-modifying therapies [92], have an impact on clinical outcomes and survival. Further, mechanistic studies are desirable to clarify the pathophysiology of asthma and 
obstructive airway disease in SCD. In this regard, the effectiveness of cysteinyl leukotriene receptor antagonist for asthma treatment in patients with SCD should be specifically addressed. Mechanistic studies and clinical trials are also needed to evaluate the effects of 5-lipoxygenase inhibitors on airway inflammation and airway hyperreactivity. Finally, the risk and benefits of regular moderate exercise activity in SCD patients should also be further investigated.

\section{Conclusion}

Chronic respiratory complications have a high burden in children with SCD and are generally associated with a more severe course of disease. Regularly investigating the presence of chronic respiratory symptoms or sleep disturbances, together with performing basic cardiorespiratory screening in the general paediatric SCD population (i.e. annual spirometry, nocturnal oximetry or PSG in patients with chronic hypoxaemia or SDB, and at least one echocardiogram before 18 years of age), might help to identify patients with early chronic respiratory complications who require further and specialist assessments. This can be particularly useful in an era of emerging disease-modifying drugs that might possibly improve also respiratory complications of patients with SCD.

Conflict of interest: None declared.

Support statement: We acknowledge the support of the European Respiratory Society (fellowship LTRF 2018).

\section{References}

1 Dormandy E, James J, Inusa B, et al. How many people have sickle cell disease in the UK? J Public Health Oxf Engl 2018; 40: e291-e295.

2 Rees DC, Williams TN, Gladwin MT. Sickle-cell disease. Lancet 2010; 376: 2018-2031.

3 Hamideh D, Alvarez O. Sickle cell disease related mortality in the United States (1999-2009). Pediatr Blood Cancer 2013; 60: 1482-1486.

4 Ruhl AP, Sadreameli SC, Allen JL, et al. Identifying clinical and research priorities in sickle cell lung disease. An Official American Thoracic Society Workshop Report. Ann Am Thorac Soc 2019; 16: e17-e32.

5 Mehari A, Klings ES. Chronic pulmonary complications of sickle cell disease. Chest 2016; 149: 1313-1324.

6 MacLean JE, Atenafu E, Kirby-Allen M, et al. Longitudinal decline in lung volume in a population of children with sickle cell disease. Am J Respir Crit Care Med 2008; 178: 1055-1059.

7 Lunt A, McGhee E, Sylvester K, et al. Longitudinal assessment of lung function in children with sickle cell disease. Pediatr Pulmonol 2016; 51: 717-723.

$8 \quad$ Koumbourlis AC. Lung function in sickle cell disease. Paediatr Respir Rev 2014; 15: 33-37.

9 Quanjer PH, Stanojevic S, Cole TJ, et al. Multi-ethnic reference values for spirometry for the 3-95-year age range: the global lung function 2012 equations. Eur Respir J 2012; 40: 1324-1343.

10 Arigliani M, Canciani MC, Mottini G, et al. Evaluation of the Global Lung Initiative 2012 Reference Values for Spirometry in African Children. Am J Respir Crit Care Med 2017; 195: 229-236.

11 Pellegrino R, Viegi G, Brusasco V, et al. Interpretative strategies for lung function tests. Eur Respir J 2005; 26 : 948-968.

12 Cohen RT, Strunk RC, Rodeghier M, et al. Pattern of lung function is not associated with prior or future morbidity in children with sickle cell anemia. Ann Am Thorac Soc 2016; 13: 1314-1323.

13 Arteta M, Campbell A, Nouraie M, et al. Abnormal pulmonary function and associated risk factors in children and adolescents with sickle cell anemia. J Pediatr Hematol Oncol 2014; 36: 185-189.

14 Arigliani M, Kitenge R, Castriotta L, et al. Lung function in children with sickle cell disease from Central Africa. Thorax 2019; 74: 604-606.

15 Arigliani M, Castriotta L, Zubair R, et al. Differences in lung function between children with sickle cell anaemia from West Africa and Europe. Thorax 2019; 74: 1154-1160.

16 Lunt A, Mortimer L, Rees D, et al. Heterogeneity of respiratory disease in children and young adults with sickle cell disease. Thorax 2018: 73: 575-577.

17 McLaren A, Klingel M, Behera S, et al. Effect of hydroxyurea therapy on pulmonary function in children with sickle cell anemia. Am J Respir Crit Care Med 2017; 195: 689-691.

18 Wedderburn CJ, Rees D, Height S, et al. Airways obstruction and pulmonary capillary blood volume in children with sickle cell disease. Pediatr Pulmonol 2014; 49: 716-722.

19 Sylvester KP, Desai SR, Wells AU, et al. Computed tomography and pulmonary function abnormalities in sickle cell disease. Eur Respir J 2006; 28: 832-838.

20 Field JJ, Burdick MD, DeBaun MR, et al. The role of fibrocytes in sickle cell lung disease. PLoS One 2012; 7: e33702.

21 Mehrad B, Burdick MD, Wandersee NJ, et al. Circulating fibrocytes as biomarkers of impaired lung function in adults with sickle cell disease. Blood Adv 2017; 1: 2217-2224.

22 Lunt A, Desai SR, Wells AU. Pulmonary function, CT and echocardiographic abnormalities in sickle cell disease. Thorax 2014; 69: 746-751.

23 Kassim AA, Payne AB, Rodeghier M, et al. Low forced expiratory volume is associated with earlier death in sickle cell anemia. Blood 2015; 126: 1544-1550.

24 Boyd JH, Macklin EA, Strunk RC, et al. Asthma is associated with acute chest syndrome and pain in children with sickle cell anemia. Blood 2006; 108: 2923-2927.

25 An P, Barron-Casella EA, Strunk RC, et al. Elevation of IgE in children with sickle cell disease is associated with doctor diagnosis of asthma and increased morbidity. J Allergy Clin Immunol 2011; 127: 1440-1446.

26 Strunk RC, Cohen RT, Cooper BP, et al. Wheezing symptoms and parental asthma are associated with a physician diagnosis of asthma in children with sickle cell anemia. J Pediatr 2014; 164: 821-826.

27 Boyd JH, Macklin EA, Strunk RC, et al. Asthma is associated with increased mortality in individuals with sickle cell anemia. Haematologica 2007; 92: 1115-1118. 
28 Miller AC, Gladwin MT. Pulmonary complications of sickle cell disease. Am J Respir Crit Care Med 2012; 185: $1154-1165$.

29 Field JJ, Stocks J, Kirkham FJ, et al. Airway hyperresponsiveness in children with sickle cell anemia. Chest 2011; 139: 563-568.

30 Andemariam B, Adami AJ, Singh A, et al. The sickle cell mouse lung: proinflammatory and primed for allergic inflammation. Transl Res 2015; 166: 254-268.

31 Wallace KL, Marshall MA, Ramos SI, et al. NKT cells mediate pulmonary inflammation and dysfunction in murine sickle cell disease through production of IFN-gamma and CXCR3 chemokines. Blood 2009; 114: 667-676.

32 De A, Manwani D, Rastogi D. Airway inflammation in sickle cell disease: a translational perspective. Pediatr Pulmonol 2018; 53: 400-411.

33 Setty BNY, Stuart MJ. Eicosanoids in sickle cell disease: potential relevance of neutrophil leukotriene B4 to disease pathophysiology. J Lab Clin Med 2002; 139: 80-89.

34 Jennings JE, Ramkumar T, Mao J, et al. Elevated urinary leukotriene E4 levels are associated with hospitalization for pain in children with sickle cell disease. Am J Hematol 2008; 83: 640-643.

35 De A, Agrawal S, Morrone K, et al. Airway inflammation and lung function in sickle cell disease. Pediatr Allergy Immunol Pulmonol 2019; 32: 92-102.

36 Koumbourlis AC, Zar HJ, Hurlet-Jensen A, et al. Prevalence and reversibility of lower airway obstruction in children with sickle cell disease. J Pediatr 2001; 138: 188-192.

37 Radhakrishnan DK, Bendiak GN, Mateos-Corral D, et al. Lower airway nitric oxide is increased in children with sickle cell disease. J Pediatr 2012; 160: 93-97.

38 Sullivan KJ, Kissoon N, Duckworth LJ, et al. Low exhaled nitric oxide and a polymorphism in the NOS I gene is associated with acute chest syndrome. Am J Respir Crit Care Med 2001; 164: 2186-2190.

39 Chaudry RA, Rosenthal M, Bush A, et al. Reduced forced expiratory flow but not increased exhaled nitric oxide or airway responsiveness to methacholine characterises paediatric sickle cell airway disease. Thorax 2014; 69: 580-585.

40 Cohen RT, Rodeghier M, Kirkham FJ, et al. Exhaled nitric oxide: not associated with asthma, symptoms, or spirometry in children with sickle cell anemia. J Allergy Clin Immunol 2016; 138: 1338-1343.

41 DeBaun MR, Strunk RC. The intersection between asthma and acute chest syndrome in children with sickle-cell anaemia. The Lancet 2016; 387: 2545-2553.

42 Caboot JB, Allen JL. Hypoxemia in sickle cell disease: significance and management. Paediatr Respir Rev 2014; 15 $17-23$.

43 Darbari DS, Fasano RS, Minniti CP, et al. Severe vaso-occlusive episodes associated with use of systemic corticosteroids in patients with sickle cell disease. J Natl Med Assoc 2008; 100: 948-951.

44 British Thoracic Society. BTS/SIGN British Guideline on the Management of Asthma. www.brit-thoracic.org.uk/ quality-improvement/guidelines/asthma/ Date last updated: April 2020; date last accessed: 20 September 2019.

45 Global Initiative for Asthma. Global Strategy for Asthma Management and Prevention, 2020. Available from: www.ginasthma.org

46 Knight-Perry J, DeBaun MR, Strunk RC, et al. Leukotriene pathway in sickle cell disease: a potential target for directed therapy. Expert Rev Hematol 2009; 2: 57-68.

47 Benard B, Bastien V, Vinet B, et al. Neuropsychiatric adverse drug reactions in children initiated on montelukast in real-life practice. Eur Respir J 2017; 50: 1700148.

48 Wallerstedt SM, Brunlöf G, Sundström A, et al. Montelukast and psychiatric disorders in children. Pharmacoepidemiol Drug Saf 2009; 18: 858-864.

49 Liu AH, Zeiger R, Sorkness C, et al. Development and cross-sectional validation of the Childhood Asthma Control Test. J Allergy Clin Immunol 2007; 119: 817-825.

50 Rosen CL, Debaun MR, Strunk RC, et al. Obstructive sleep apnea and sickle cell anemia. Pediatrics 2014; 134: 273-281.

51 Quinn CT, Ahmad N. Clinical correlates of steady-state oxyhaemoglobin desaturation in children who have sickle cell disease. Br J Haematol 2005; 131: 129-134.

52 Halphen I, Elie C, Brousse V, et al. Severe nocturnal and postexercise hypoxia in children and adolescents with sickle cell disease. PloS One 2014; 9: e97462.

53 Abdu A, Gómez-Márquez J, Aldrich TK. The oxygen affinity of sickle hemoglobin. Respir Physiol Neurobiol 2008; 161: $92-94$

54 Needleman JP, Setty BN, Varlotta L, et al. Measurement of hemoglobin saturation by oxygen in children and adolescents with sickle cell disease. Pediatr Pulmonol 1999; 28: 423-428.

55 Caboot JB, Jawad AF, McDonough JM, et al. Non-invasive measurements of carboxyhemoglobin and methemoglobin in children with sickle cell disease. Pediatr Pulmonol 2012; 47: 808-815.

56 Leach RM, Treacher DF. Oxygen transport-2. Tissue hypoxia. BMJ 1998; 317: 1370-1373.

57 Gileles-Hillel A, Kheirandish-Gozal L, Gozal D. Hemoglobinopathies and sleep: the road less traveled. Sleep Med Rev 2015; 24: 57-70.

58 Dlamini N, Saunders DE, Bynevelt $\mathrm{M}$, et al. Nocturnal oxyhemoglobin desaturation and arteriopathy in a pediatric sickle cell disease cohort. Neurology 2017; 89: 2406-2412.

59 Kirkham FJ, Hewes DKM, Prengler M, et al. Nocturnal hypoxaemia and central-nervous-system events in sickle-cell disease. Lancet 2001; 357: 1656-1659.

60 Quinn CT, Sargent JW. Daytime steady-state haemoglobin desaturation is a risk factor for overt stroke in children with sickle cell anaemia. Br J Haematol 2008; 140: 336-339.

61 Johnson MC, Kirkham FJ, Redline S, et al. Left ventricular hypertrophy and diastolic dysfunction in children with sickle cell disease are related to asleep and waking oxygen desaturation. Blood 2010; 116: 16-21.

62 Minniti CP, Sable C, Campbell A, et al. Elevated tricuspid regurgitant jet velocity in children and adolescents with sickle cell disease: association with hemolysis and hemoglobin oxygen desaturation. Haematologica 2009; 94: 340-347.

63 Pashankar FD, Carbonella J, Bazzy-Asaad A, et al. Prevalence and risk factors of elevated pulmonary artery pressures in children with sickle cell disease. Pediatrics 2008; 121: 777-782.

64 Willen SM, Rodeghier M, Rosen CL, et al. Sleep disordered breathing does not predict acute severe pain episodes in children with sickle cell anemia. Am J Hematol 2018; 93: 478-485. 
65 Uong EC, Boyd JH, Debaun MR. Daytime pulse oximeter measurements do not predict incidence of pain and acute chest syndrome episodes in sickle cell anemia. J Pediatr 2006; 149: 707-709.

66 Sickle Cell Society, Public Health England. Sickle Cell Disease in Childhood: Standards and Recommendations for Clinical Care. 3rd Edn. London, Sickle Cell Society, 2019.

67 Ahmedzai S, Balfour-Lynn IM, Bewick T, et al. Managing passengers with stable respiratory disease planning air travel: British Thoracic Society recommendations. Thorax 2011; 66: Suppl. 1, i1-30.

68 Willen SM, Thornburg CD, Lantos PM. The traveler with sickle cell disease. J Travel Med 2014; 21: 332-339.

69 Kaditis AG, Alonso Alvarez ML, Boudewyns A, et al. Obstructive sleep disordered breathing in 2- to 18-year-old children: diagnosis and management. Eur Respir J 2016; 47: 69-94.

70 van Geyzel L, Arigliani M, Inusa B, et al. Higher oxygen saturation with hydroxyurea in paediatric sickle cell disease. Arch Dis Child 2020: 105: 575-579.

71 Qureshi A, Kaya B, Pancham S, et al. Guidelines for the use of hydroxycarbamide in children and adults with sickle cell disease. Br J Haematol 2018; 181: 460-475.

72 Hayes D, Wilson KC, Krivchenia K, et al. Home oxygen therapy for children. An Official American Thoracic Society Clinical Practice Guideline. Am J Respir Crit Care Med 2019; 199: e5-e23.

73 Haase VH. Regulation of erythropoiesis by hypoxia-inducible factors. Blood Rev 2013; 27: 41-53.

74 Embury SH, Garcia JF, Mohandas N, et al. Effects of oxygen inhalation on endogenous erythropoietin kinetics, erythropoiesis, and properties of blood cells in sickle-cell anemia. N Engl J Med 1984; 311: 291-295.

75 Reinhard EH, Moore CV, Dubach R, et al. Depressant effects of high concentrations of inspired oxygen on erythrocytogenesis. Observations on patients with sickle cell anemia with a description of the observed toxic manifestations of oxygen 12. J Clin Invest 1944; 23: 682-698.

76 Ip H, Kesse-Adu R, Howard J, et al. Low flow nocturnal oxygen therapy does not suppress haemoglobin levels or increase painful crises in sickle cell disease. Br J Haematol 2013; 161: 455-456.

77 Waltz X, Romana M, Hardy-Dessources M-D, et al. Hematological and hemorheological determinants of the six-minute walk test performance in children with sickle cell anemia. PLoS One 2013; 8: e77830.

78 Liem RI, Reddy M, Pelligra SA, et al. Reduced fitness and abnormal cardiopulmonary responses to maximal exercise testing in children and young adults with sickle cell anemia. Physiol Rep 2015; 3: e12338.

79 Alsaied T, Niss O, Powell AW, et al. Diastolic dysfunction is associated with exercise impairment in patients with sickle cell anemia. Pediatr Blood Cancer 2018; 65: e27113.

80 Powell AW, Alsaied T, Niss O, et al. Abnormal submaximal cardiopulmonary exercise parameters predict impaired peak exercise performance in sickle cell anemia patients. Pediatr Blood Cancer 2019; 66: e27703.

81 Liem RI, Nevin MA, Prestridge A, et al. Functional capacity in children and young adults with sickle cell disease undergoing evaluation for cardiopulmonary disease. Am J Hematol 2009; 84: 645-649.

82 Gordeuk VR, Minniti CP, Nouraie M, et al. Elevated tricuspid regurgitation velocity and decline in exercise capacity over 22 months of follow up in children and adolescents with sickle cell anemia. Haematologica 2011; 96: 33-40.

83 Connes $\mathrm{P}$, Machado R, Hue O, et al. Exercise limitation, exercise testing and exercise recommendations in sickle cell anemia. Clin Hemorheol Microcirc 2011; 49: 151-163.

84 Liem RI. Balancing exercise risk and benefits: lessons learned from sickle cell trait and sickle cell anemia. Hematol Am Soc Hematol Educ Program 2018; 2018: 418-425.

85 Fonseca GHH, Souza R, Salemi VMC, et al. Pulmonary hypertension diagnosed by right heart catheterisation in sickle cell disease. Eur Respir J 2012; 39: 112-118

86 Parent F, Bachir D, Inamo J, et al. A hemodynamic study of pulmonary hypertension in sickle cell disease. $N$ Engl J Med 2011; 365: 44-53.

87 Simonneau G, Montani D, Celermajer DS, et al. Haemodynamic definitions and updated clinical classification of pulmonary hypertension. Eur Respir J 2019; 53: 1801913.

88 Gordeuk VR, Castro OL, Machado RF. Pathophysiology and treatment of pulmonary hypertension in sickle cell disease. Blood 2016; 127: 820-828.

89 Klings ES, Machado RF, Barst RJ, et al. An official American Thoracic Society clinical practice guideline: diagnosis, risk stratification, and management of pulmonary hypertension of sickle cell disease. Am J Respir Crit Care Med 2014; 189: 727-740.

90 Frost A, Badesch D, Gibbs JSR, et al. Diagnosis of pulmonary hypertension. Eur Respir J 2019: 53: 1801904.

91 Ambrusko SJ, Gunawardena S, Sakara A, et al. Elevation of tricuspid regurgitant jet velocity, a marker for pulmonary hypertension in children with sickle cell disease. Pediatr Blood Cancer 2006; 47: 907-913.

92 Tisdale JF, Thein SL, Eaton WA. Treating sickle cell anemia. Science 2020; 367: 1198-1199. 